\title{
TALENTOS EM GESTÃO E GESTÃO DE TALENTOS: ANÁLISE DA LITERATURA ACADÊMICA E DE PRÁTICAS CORPORATIVAS ${ }^{1}$
}

\author{
Bárbara Beatriz Freitag ${ }^{2}$ \\ André Luiz Fischer ${ }^{3}$
}

http://dx.doi.org/10.1590/1413-2311.152.54930

\begin{abstract}
RESUMO
A produção acadêmica sobre Gestão de Talentos é emergente, poucos são os estudos dedicados a entender o seu desenvolvimento teórico. O objetivo principal deste estudo foi analisar os conceitos de talento e gestão de talentos na produção acadêmica de Administração e a sua utilização no meio corporativo. É um estudo predominantemente descritivo, composto de levantamento da literatura e por dados empíricos referentes à definição de Talentos adotada por 471 organizações no Brasil. Os dados foram analisados por meio da análise de conteúdo com a técnica de análise da expressão e suporte do software NVIVO 10. Foram analisadas as definições de talento declaradas pelas empresas em relação à literatura deste tema. Verificouse que para cada empresa há uma definição de talento. Entretanto, há termos que se repetem nestas definições. Assim, foi gerada uma lista com as palavras mais frequentes para se referir a talento. A análise agregada dessa lista em relação à literatura de talentos e a de GT possibilitou consolidar os termos principais em duas categorias de atributos de Talento, sendo eles: os identificadores e os qualificadores. Este estudo se limitou ao estilo descritivo e se restringiu à utilização de dados secundários o que não permitiu análises em profundidade. Sugerem-se para estudos futuros, técnicas de estudo de caso longitudinais e pesquisas que busquem identificar como as empresas podem operacionalizar a GT de modo estratégico.
\end{abstract}

Palavras-chave: Talento. Gestão de Talentos. Gestão Estratégica de Pessoas.

TALENT MANAGEMENT AND MANAGEMENT OF TALENTS: ACADEMIC LITERATURE ANALYSIS AND CORPORATIVE PRACTICES

\begin{abstract}
The academic production on Talent Management (TM) is emergent, there are few studies dedicated to understanding its theoretical development. The main goal of this study is to analyze the concepts of talent and TM on Administration academic production and its corporative use. It is a mostly a descriptive study, encompassing literature analysis and
\end{abstract}

\footnotetext{
${ }^{1}$ Recebido em 17/04/2015; aprovado em 23/07/2017.

${ }^{2}$ Universidade de São Paulo - barbara.adm@gmail.com.

${ }^{3}$ Universidade de São Paulo - afischer@usp.br.

REAd | Porto Alegre - Vol. 23 - No Especial - Dezembro 2017 - p. 158-187
} 
empiric data related to the talent definition adopted by 471 organizations in Brazil. Data were analyzed using content analysis with the expression analysis technique and NVIVO 10 software. Considering the literature on this theme, the analysis of the definitions of Talent declared by the companies revealed that there is a talent definition to each company, but there are terms that are common on these different definitions. From that, was generated a list with the most frequent words by company category. The joint analysis of this list with the literature on talent and TM has made possible to consolidate two talent attribute categories: identifiers and qualifiers. This study is limited to descriptive analysis and the use of secondary data; therefore it was not possible to proceed with in depth analysis. It is suggested to future studies the use of techniques such as longitudinal case study and the pursue of themes such as the identification of how companies can operate the Talent Management in a strategic way.

Keywords: Talent. Talent Management. Strategic Human Resource Management.

\title{
TALENTOS EN LA GESTIÓN Y GESTIÓN DEL TALENTO: ANÁLISIS DE LA PRODUCCIÓN ACADÊMICA Y PRÁCTICAS EMPRESARIALES
}

\begin{abstract}
RESUMEN
La producción académica acerca de la gestión del talento es emergente, pocos son los estudios dedicados a entender su desarrollo teórico. El objetivo principal de este estudio fue analizar los conceptos de talento y la gestión del talento en la producción académica de Administración y su uso empresarial. Se trata de un estudio descriptivo, que abarca el análisis de la literatura y de los datos empíricos relacionados con la definición de talento aprobada por 471 organizaciones en Brasil. Los datos fueron analizados por análisis de contenido con la técnica de análisis de la expresión y el software NVIVO 10. Se analizaron conceptos de Talento reportados por las empresas em relación con la literatura de este tema. Se encontró que por cada empresa hay una definición de Talento, mientras hay termos que se repiten en las distintas definiciones. Así se creó una lista de las palabras más frecuentes en relación con la literatura analizada. Esto hizo posible la consolidación de las palabras clave en dos categorías de atributos de talento, a saber: los identificadores y los calificadores. Este estudio está limitado al estilo descriptivo y se restringió a los datos secundarios, así que no se hicieron análisis en profundidad. Para estudios futuros se sugieren técnicas de estudio de caso longitudinales e investigaciones para señalar cómo las empresas pueden operar la Gestión de Talentos estratégicamente.
\end{abstract}

Palabras clave: Talento. Gestión del Talento. Gestión Estratégica de Personas.

\section{INTRODUÇÃO}

As economias globais e a tecnologia derrubaram barreiras, uma delas foi a do mercado de trabalho que passou a ser global, em função da mobilidade e acessibilidade do mundo moderno. As atividades e serviços passaram a ser mais complexos, demandando uma força de 
trabalho melhor qualificada e especializada (LEGGE, 2005). Isso fez com que as empresas deixassem de ser as únicas protagonistas na oferta de emprego e passassem a competir mais intensamente pelos profissionais mais talentosos.

Essa mudança de cenário trouxe desafios para a GRH, que passou a lidar com estruturas internacionalizadas, mais complexas e ágeis, impactando estrategicamente sua relação com o mercado e com as pessoas. Pesquisas internacionais e nacionais do final da década de 1990 e dos anos 2000 apontaram fortemente que, para se manterem num ambiente de aumento da concorrência global pelo emprego e pela busca por Talentos, as organizações teriam que investir em atrair, desenvolver e reter os melhores profissionais (SRHM, 2011; FISCHER; ALBUQUERQUE, 2010). Com isso, passou a figurar, entre os temas prioritários de RH, a Gestão de Talentos.

No meio acadêmico nacional e internacional, houve uma produção considerável de artigos e teses abordando esse assunto (FREITAG et al., 2012). Estes foram, predominantemente, desenvolvidos com uma perspectiva crítica, na intenção de identificar semelhanças ou diferenças da GT com a GRH e verificar se esta não era só mais uma nomenclatura nova para a área da gestão de pessoas. Também, houve trabalhos com foco na retenção dos talentos, influenciados pelo termo "guerra por talentos", disseminado pela pesquisa publicada pela consultoria McKinsey em 1998 (AXELROD et al., 2001). Poucos foram os estudos que se propuseram entender o desenvolvimento conceitual deste assunto. Mas a partir de meados dos anos 2000 eles começaram a surgir, internacionalmente, nos moldes de revisões desta literatura. Em 2006, Lewis e Heckman apontaram que o termo "Gestão de Talentos" era polêmico, pouco definido, confundindo-se, para alguns pesquisadores e profissionais, com práticas tradicionais de $\mathrm{RH}$.

Diante do contexto apresentado é possível constatar na diversidade conceitual de talento, de sua gestão e abordagens teóricas um problema de pesquisa a ser discutido. Este é o campo de investigação deste estudo, ele se propõe a contribuir com a literatura sobre Gestão de Recursos Humanos e sobre Gestão de Talentos, analisando a produção acadêmica nacional e internacional e relacionando-a com a sua prática em organizações que atuam no Brasil. Para isso foi proposto como objetivo principal da pesquisa: analisar os conceitos de talento e gestão de talentos na produção acadêmica de Administração e a sua utilização no meio corporativo.

Além dessa introdução, em que se contextualizou o problema de pesquisa a ser REAd | Porto Alegre - Vol. 23 - No Especial - Dezembro 2017 - p. 158-187 
discutido e o objetivo central do estudo, este artigo foi organizado nas seguintes seções: referencial teórico, metodologia, apresentação e análise dos resultados, considerações finais e referências.

\section{REFERENCIAL TEÓRICO}

Na seção de referencial teórico consta um panorama da Gestão de Talentos no âmbito da Gestão de Pessoas no campo da Administração.

\subsection{GESTÃO DE TALENTOS NO ÂMBITO DA GESTÃO DE PESSOAS NO CAMPO DA ADMINISTRAÇÃO}

O campo de estudos da Gestão de Pessoas (GP) ou de Recursos Humanos (RH) foi definido neste estudo como contexto teórico para a discussão de Gestão de Talentos (GT), uma vez que uma definição abrangente e atual para essa área considera que ela envolve todas as atividades da gestão do trabalho das pessoas nas organizações (BOXALL; PURCELL, 2008). Cabe esclarecer que não há a pretensão de realizar uma revisão exaustiva da literatura dos temas enunciados. Sobre RH e Gestão Estratégica de RH (GERH) já há uma consolidada e abrangente produção acadêmica. Assim, considera-se que a análise da evolução e estrutura destes campos teóricos pode auxiliar no entendimento da literatura que leva às reflexões sobre Gestão de Talentos nas organizações.

Nas análises do estado da arte em GRH realizadas por Ferris et al. (1999), Boxall et al. (2008) e Martin-Alcázar et al. (2008) constatou-se que os principais subdomínios dessa área são: (1) Micro ou Funcional que envolve as funções, políticas e práticas de RH; (2) Macro ou Estratégico que foca nas questões sistêmicas e globais de $\mathrm{RH}$ e na tentativa de mensurar o impacto destas na performance organizacional; (3) Internacional, cujo foco é na GRH das organizações que operam através das fronteiras nacionais e está conectado com as questões relacionadas aos negócios internacionais e à internacionalização.

O desenvolvimento e popularização do conceito de gestão estratégica, oriundo de Michael Porter e Igor Ansoff, entre outros, (BOXALL; PURCELL, 2008) possibilitou a realização de pesquisas e publicações sobre os aspectos estratégicos da GRH. Estes estudos, desenvolvidos a partir da década de 1980 foram se consolidando a ponto de se definir como um novo subcampo chamado "Strategic Human Resource Management (SHRM)" ou "Gestão 
Estratégica de Recursos Humanos (GEHR)" (KAUFMAN, 2008). Na perspectiva de Wright e Macmahan (1992) a GERH é considerada como o planejamento da gestão de pessoas com vistas ao alcance dos objetivos organizacionais. Neste paradigma, a GERH estaria alinhada aos objetivos estratégicos da organização para maximizar os seus recursos a partir da atração, seleção e retenção da pessoa certa para uma atividade específica (MILES; SNOW, 1984).

Revisando a literatura de GERH, Lengnick-Hall et al. (2009) constataram que há três estratos para categorizá-la, cada qual com distintos tipos de fit (consistência) e grau de flexibilidade: (1) Best Practice ou Universalista - melhor prática de GRH que contribui para o crescimento da performance independente dos objetivos estratégicos da organização; (2) Contingencial - implica a seleção de uma teoria da estratégia organizacional e, em seguida, a especificação de como cada prática de RH isoladamente irá interagir com a estratégia da empresa resultando na performance organizacional; (3) Configuracional - perspectiva holística (sistemas) da organização.

Wright e McMahan (1992) verificaram, na literatura da área, possíveis aplicações das teorias de nível macro da organização para o campo de GERH e apresentaram seis modelos teóricos: (1) Teorias Não-Estratégicas: Teoria Institucional; Modelos de Poder; (2) Teorias Estratégicas: Teoria Comportamental; Teoria de Sistemas; Teoria da Agência; Teoria da Firma Baseada em Recursos (Resource-based view of the firm (RBV)). A perspectiva da RBV seria a mais recente no campo da GERH, é de cunho estratégico e se mostra coerente com um contexto de mercado altamente competitivo em que a busca pela vantagem competitiva entre as organizações ocorre a partir de seus recursos, inclusive os humanos (WRIGHT; MCMAHAN, 1992).

$\mathrm{Na}$ ótica da RBV aplicada à GERH, os recursos humanos são vistos como um importante recurso organizacional por ser valioso, raro, inimitável e difícil de substituir (BARNEY; WRIGHT, 1998). Quando as empresas dispõem desse tipo de recurso podem implementar estratégias de criação de valor baseadas nas pessoas como vantagem, uma vez que controlam um recurso escasso, os melhores profissionais (BARNEY, 1991; WRIGHT et al., 2001).

Essa síntese procura demonstrar que a GERH pode ser analisada como um subdomínio da GRH (BOXALL et al., 2008) a partir de suas três abordagens principais: universalista, contingencial e configuracional (LENGNICK-HALL et al., 1999). Os fundamentos dos estudos sobre GERH advêm de teorias macro sobre a organização, sendo a RBV uma delas

REAd | Porto Alegre - Vol. 23 - No Especial - Dezembro 2017 - p. 158-187 
(WRIGHT; MCMAHAN, 1992). Ao relacionar GERH e RBV, observa-se que a obtenção de diferenciais competitivos vem sendo o discurso predominante no meio corporativo, tornandose uma condição fundamental para a perpetuidade e desenvolvimento das organizações. Desdobramentos da teoria de GERH abrem espaço para estudos de cunho estratégico para as organizações, tais como sistemas flexíveis e variados com práticas distintas definidas de acordo com a performance e potencial dos profissionais. Estes são os elementos teóricos e contextuais que vêm promovendo e sustentando a tendência desse campo em priorizar a Gestão de Talentos.

Este movimento vem estimulando a produção acadêmica sobre o tema Gestão de Talentos. As pesquisas de revisão da literatura sobre este tema constataram um avanço quantitativo e conceitual a partir de meados dos anos 2000 (FREITAG; FISCHER, 2013). Lewis e Heckman (2006) produziram um estudo no qual identificaram e categorizaram definições conceituais sobre GT. Ao longo daquele levantamento, os autores constataram as seguintes classificações: (1) GT são práticas típicas do departamento e funções de RH. Seria como fazer o que RH sempre fez, só que mais rápido; (2) GT se concentra sobre o conceito de talent pools ou banco de talentos; (3) GT como gestão genérica de Talento desconsiderando as fronteiras da organização ou de posições específicas, atuando com a diferenciação pela performance.

Estudos posteriores fizeram tentativas de definir conceitualmente este campo teórico, tal como consta na citação a seguir: "A Gestão de Talentos é a abordagem coletiva para recrutar, reter e desenvolver talentos dentro da organização para seu benefício futuro" (ILES et al., 2010, p.181, tradução livre). As práticas que configuram um Sistema de GT aparecem, também, na literatura como voltadas para a identificação, desenvolvimento e retenção de pessoas (BERGER; BERGER, 2004; INGHAM, 2006).

Além da definição conceitual, na literatura há estudos que se propuseram analisar as características das práticas de GT e suas consequências. Por serem largamente citadas na literatura acadêmica merecem destaque as perspectivas inclusiva e a exclusiva de GT, constatadas inicialmente por Lewis e Heckman (2006) e complementadas por Iles et al. (2010). Na perspectiva inclusiva de GT todas as pessoas são consideradas como talento, o que diferencia é o enfoque da organização, sendo ele humanista ou sistêmico. Na perspectiva exclusiva, o objetivo é a diferenciação e segmentação das pessoas de acordo com seu potencial, performance ou sua posição na organização (LEWIS; HECKMAN, 2006; ILES et 
al., 2010).

A partir da literatura levantada, entende-se que a GT pode ocorrer e ser analisada nos subdomínios micro, internacional ou macro da GRH dependendo do enfoque adotado. $\mathrm{Na}$ perspectiva inclusiva, quando se consideram todos os empregados como talento, a GT se alinha ao aspecto geral da teoria de GRH, pois preza pela igualdade de tratamento. Na medida em que o objetivo da organização é a diferenciação da força de trabalho, tal como preconizado pela perspectiva exclusiva de GT, considera-se que há um alinhamento mais próximo ao proposto pelas teorias da GERH, pois busca tratar os Talentos com um diferencial competitivo da organização.

Assim, ao analisar as abordagens de GT na literatura acadêmica fica evidente a sua condição como um conjunto de práticas. As variações no estilo desta gestão dependem do entendimento que é dado ao termo Talento em cada organização. Diante disto, identificou-se um padrão conceitual que permitiu caracterizar a Gestão de Talentos como uma configuração de práticas adotada pelas organizações para gerenciar pessoas previamente definidas (ou não) como talentos. Nos casos em que as pessoas talentosas são consideradas recursos escassos, e, portanto, merecem uma configuração de práticas específicas, temos um sistema exclusivo, quando ocorre o oposto, o sistema ganha características inclusivas e todos são talentos.

Por fim, nesta seção de referencial teórico foi traçado um panorama da produção acadêmica sobre GT no âmbito da Gestão de Pessoas. Talento é um termo que, ainda, se mostra impreciso contendo um aspecto ambíguo, frequentemente sujeito às abordagens de gestão e estratégias de cada organização. Mas, independente desta condição fluída e contingencial a sua definição é considerada fundamental para a concepção de um Sistema de GT. Para tanto, a fase empírica deste estudo foi dividida em duas partes: (1) Pesquisa Bibliométrica sobre os termos talento e GT na literatura acadêmica; (2) Levantamento de dados por meio da qual foram coletadas definições de talento em uma amostra de organizações atuantes no Brasil. O procedimento metodológico da fase empírica deste estudo consta na próxima seção.

\section{PROCEDIMENTOS METODOLÓGICOS}

Neste estudo buscou-se analisar os conceitos de talento e gestão de talentos na produção acadêmica de Administração e a sua utilização no meio corporativo. Portanto, foi necessário

REAd | Porto Alegre - Vol. 23 - No Especial - Dezembro 2017 - p. 158-187 
realizar dois tipos de pesquisa, uma para captar dados da literatura e a segunda para captar os dados organizacionais. Nesta seção apresentam-se os procedimentos metodológicos da fase empírica deste estudo, na seguinte ordem: (2.1) Pesquisa Bibliométrica; (2.2) Levantamento de Dados Organizacionais.

\subsection{PESQUISA BIBLIOMÉTRICA}

O levantamento da literatura sobre talento e gestão de talentos se caracterizou por ser uma revisão sistemática, cujo objetivo é uma consolidação conceitual de um campo fragmentado a partir da coleta sistemática de dados, de análise descritiva e qualitativa, resultando na produção de uma síntese fundamentada (TRANFIELD et al., 2003; CROSSAN; APAYDIN, 2010).

Optou-se por análise temporal em séries históricas e análise bibliométrica. No que se refere à bibliometria, Alvarenga (1998) cita que os resultados encontrados refletem aspectos quantitativos de campos do conhecimento, apresentando, por exemplo, ângulos de produtividade de autores ou de fontes e constatações de regularidades que podem resultar em fatos históricos no processo de evolução de uma disciplina. Segundo Macias-Chapula (1998), a pesquisa bibliométrica pode ser caracterizada quanto ao objeto de estudo e ao método empregado. Sendo o primeiro, relativo a livros, documentos, artigos, autores, etc. E o último, à frequência e distribuição.

Esse processo de levantamento da produção acadêmica teve início com a coleta de artigos. Esta etapa iniciou-se pela definição de um período de pesquisa e foi finalizada com a listagem de periódicos pesquisados e trabalhos encontrados (CROSSAN; APAYDIN, 2010). A definição do período de pesquisa ocorreu a partir da observação de fatos relacionados à produção de literatura sobre estes temas que permitiu delimitar uma data à qual se desse início a esta revisão.

Há trabalhos que utilizam o termo Talento no campo da Gestão desde 1923 de acordo com a base Web of Science (2012), sendo que a maior concentração de publicações e citações se mostra a partir da década de 1980 e, com maior regularidade, a partir de 1998. De acordo com um levantamento preliminar, sabe-se que a discussão sobre Gestão de Talentos teve início nos anos de 1990 (FARNDALE et al., 2010). Em 1998, ocorreu a publicação da pesquisa da Consultoria Mckinsey que cunhou o termo "The War for Talent", mobilizando os profissionais e pesquisadores em torno desta questão. Portanto, neste estudo, foi estabelecido

REAd | Porto Alegre - Vol. 23 - No Especial - Dezembro 2017 - p. 158-187 
verificar a produção acadêmica destes temas desde janeiro de 1998 até dezembro de 2011, de maneira a vislumbrar o seu desenvolvimento e amadurecimento.

As fontes para a revisão da literatura acadêmica dos temas em questão foram selecionadas de modo a trazer para este estudo a produção de melhor classificação. Para tanto, optou-se por seguir índices que apontam quais são os periódicos de maior fator de impacto e de melhor qualificação tomando como base o Índice JCR, Journal Citation Reports, da base ISI Web of Knowledge, na versão 2010 e os periódicos listados no sistema WebQualis da CAPES, Coordenação de Aperfeiçoamento de Pessoal de Nível Superior, de 2010, classificados de A1 a B2. Sobre as pesquisas nacionais, optou-se, também, por analisar os artigos publicados na área de RH do Encontro Nacional da ANPAD (EnANPAD) e recorreuse ao Banco de Teses e Dissertações da FEA/USP, da BDTD, Biblioteca Digital Brasileira de Teses e Dissertações, e do Banco de Teses e Dissertações da CAPES pesquisando Teses e Dissertações de cursos de Pós-Graduação na área de Administração no Brasil.

Além de artigos e monografias, esta revisão de literatura também resultou na seleção de três livros: o "Talent \& Society" do McClelland et al. (1958); "The Talent Management Handbook" de Berger e Berger (2004); e o "The War for Talent" de Handfield-Jones e Axelrod (2001). Considerou-se que estas obras são importantes para este estudo, porque a primeira trata-se de um livro clássico sobre o tema; o segundo por ser um handbook e trazer uma abordagem abrangente e atual. E, a terceira obra é a publicação que resultou da pesquisa da Mckinsey de 1998 que cunhou o termo "The War for Talent", de grande impacto no meio profissional.

A revisão de literatura foi realizada em duas fases. Uma mecânica, em que se buscou pelos textos mais citados sobre o assunto pesquisado desde o primeiro ano (1898), disponibilizado pela base consultada (Web of Science, 2012). Na fase manual, em que se buscou levantar a quantidade de publicações sobre o tema, foram consultados todos os volumes e números das fontes selecionadas no período de janeiro de 1998 a dezembro de 2011. Optou-se por acrescentar a busca manual nessa etapa e não utilizar as ferramentas de busca automática dos sites consultados, a fim de obter uniformidade no processo, já que eram diversos tipos de fontes a serem exploradas e não havia uma homogeneidade no critério das ferramentas disponibilizadas. A síntese das etapas, critérios e quantidade de textos selecionados nesta pesquisa consta na Tabela 1 .

REAd | Porto Alegre - Vol. 23 - No Especial - Dezembro 2017 - p. 158-187 
Tabela 1 - Síntese da Revisão de Literatura sobre Talento em Gestão e GT

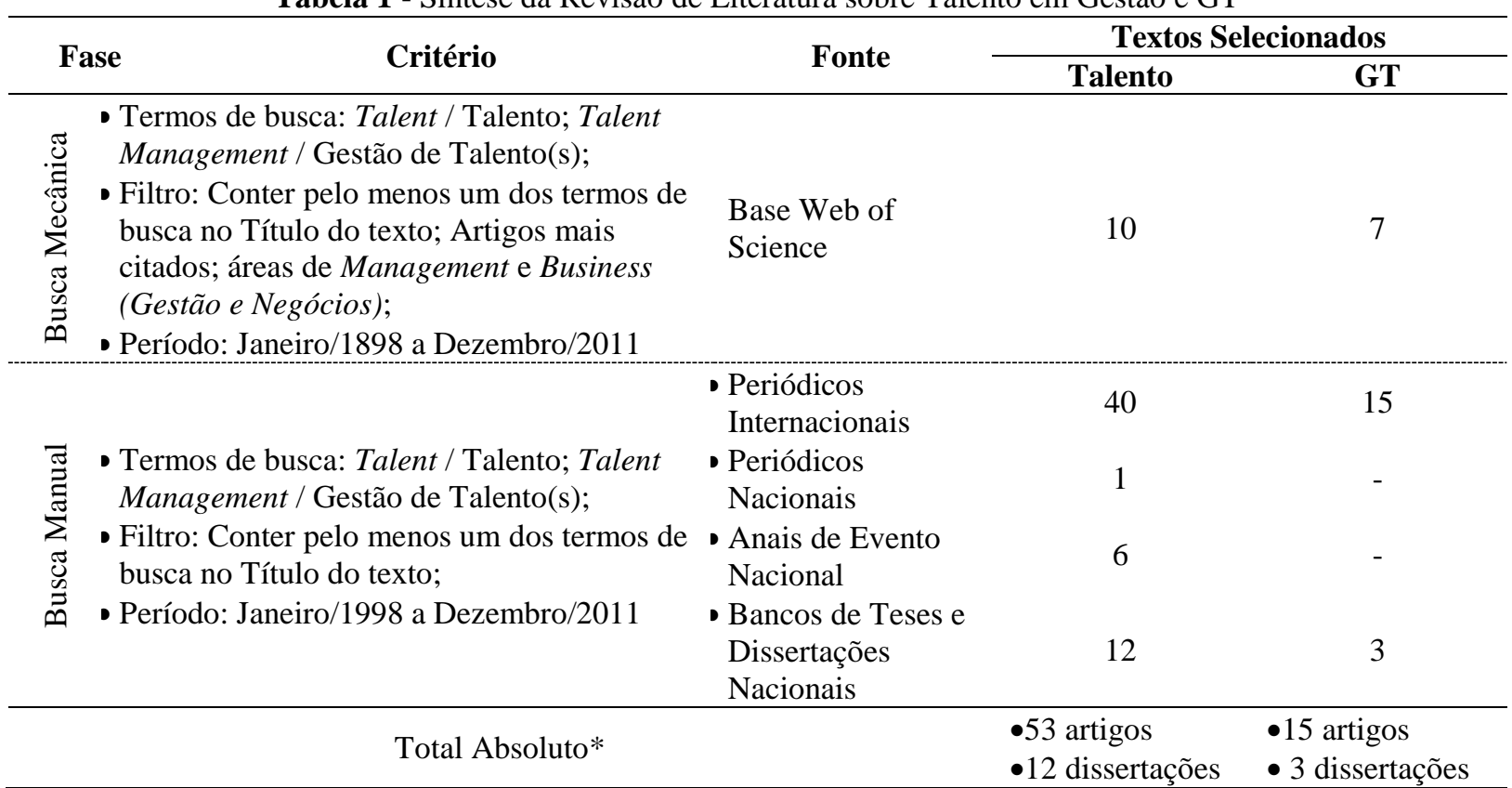

*Os textos de GT estão contidos na seleção de Talento. Alguns textos da busca mecânica também foram encontrados na busca manual, por isso, o total apresentado é o absoluto por categoria.

Fonte: elaborado pelos autores.

Este levantamento resultou na seleção absoluta de 53 artigos e 12 dissertações de mestrado no período analisado, sendo que os textos de GT estão contidos na seleção dos artigos sobre Talento. Desta seleção, quatro artigos, que constam entre os 10 mais citados sobre estes temas na base Web of Science, estão contidos, também, entre os textos selecionados na fase manual desta pesquisa. Isto dá credibilidade para o método adotado e demonstra que o período selecionado (1998 a 2011) é representativo da contemporaneidade desta literatura. Os seis textos restantes desta categoria (mais citados) estão distribuídos nos outros 74 anos de publicações (1923-1997), conforme a base Web of Science (2012). Na Tabela 1, pôde-se observar que a produção de artigos sobre esses assuntos é, em sua maioria, de fonte internacional.

Os textos selecionados tiveram seus arquivos salvos nos softwares Mendeley e NVivo, a fim de auxiliar na organização e análise do material, respectivamente. Os itens selecionados foram processados e organizados nesta pesquisa na forma apresentada abaixo.

(a) Leitura dos resumos e leitura flutuante de todos os textos e dissertações selecionadas a fim de encontrar capítulos e ou definições sobre Talentos ou Gestão de Talentos.

(b) Classificação dos trabalhos selecionados nas seguintes categorias: ano e fonte; uso do termo de busca - menção a Talento ou GT, definição sobre Talento ou GT, uso de Talento ou

REAd | Porto Alegre - Vol. 23 - No Especial - Dezembro 2017 - p. 158-187 
GT somente no título.

(c) Leitura completa: três artigos de Revisão, sendo um de GT, um de Gestão Estratégica de Talentos e outra de Gestão Global de Talentos; dois textos que trouxeram, simultaneamente, definições de Talento e de GT; texto nacional mais citado nas dissertações.

A análise desta revisão foi prioritariamente quantitativa, sendo apresentada descritivamente de acordo com distribuição e frequência. Para verificar o uso do termo de busca e analisar os conceitos e caracterizações de Talento e GT, houve uma fase qualitativa com análise de conteúdo. Nesta última fase, foram utilizados os recursos de contagem e busca de palavras do software NVivo. Ao todo, foram considerados 52 artigos para a fase de análise, isto ocorreu porque não foi possível fazer o download de um deles e, também, porque quatro textos da busca mecânica se repetiram na busca manual. Os resultados da análise do material coletado constam na seção de apresentação e análise dos resultados, na subseção 3.1.

\subsection{LEVANTAMENTO DE DADOS ORGANIZACIONAIS}

O delineamento da pesquisa de levantamento de dados, os instrumentos de coleta de dados, a população, amostra e técnicas adotadas para análise dos dados empíricos são apresentados nesta subseção.

Esse artigo faz parte de uma pesquisa mais ampla e de acordo com o objetivo principal desse estudo, pode-se caracterizá-lo como exploratório e descritivo. Inicialmente, é exploratório, haja vista, que o levantamento prévio da literatura demonstrou que a questão dos talentos no campo da gestão ainda é imprecisa e pouco desenvolvida (LEWIS; HECKMAN, 2006). Descritivo, porque se dedicou a coletar informações sobre a literatura e as organizações que praticam a GT, as quais foram analisadas e descritas neste estudo. A abordagem descritiva, entre outras, é considerada apropriada para estudos formais e estruturados com o objetivo de descrever fenômenos ou características, estimar proporções e relacionar diferentes variáveis de uma população (SELLTIZ et al., 1987).

Os dados empíricos utilizados são de origem secundária, tendo sido captados de forma direta por meio de uma survey mais ampla, realizada anualmente pelo grupo de pesquisa de Gestão de Pessoas e Gestão do Conhecimento nas Organizações sediado na FEA-USP. Foram utilizados dados de 2010, já que neste ano foram inseridas no referido instrumento de pesquisa questões específicas sobre Gestão de Talentos. Essa base de dados foi elaborada, 
portanto, a partir da técnica de levantamento, que é adequada para obter informações de um conjunto definido de pessoas, ou de uma população (EASTERBY-SMITH et al., 1999).

O instrumento utilizado para a coleta de dados foi o questionário. Segundo EasterbySmith et al. (1999), o formulário é amplamente usado em trabalhos que utilizam a técnica de levantamento ou survey. Para este estudo, foi adotado o questionário da survey realizada com a metodologia do grupo de pesquisa de Gestão de Pessoas e Gestão do Conhecimento nas Organizações sediado na FEA-USP. Grupo de pesquisa que coleta, anualmente, dados de empresas que pretendem ser reconhecidas pela qualidade do seu ambiente de trabalho e de suas práticas de GRH. Para este estudo foi considerada a edição de 2010 da pesquisa citada. O questionário adotado nesta pesquisa é composto, predominantemente, por perguntas fechadas. E na edição de 2010 foram inseridas cinco questões abertas e específicas sobre Gestão de Talentos. Foram selecionadas e analisadas 46 questões fechadas e abertas que se relacionavam diretamente com o objetivo proposto neste artigo. As questões selecionadas podem ser classificadas em quatro categorias, são elas: (1) Perfil das empresas e dos empregados; (2) Diretrizes Estratégicas Organizacionais e de RH; (3) Programa Formal de GT e (4) Definições de Talento.

Este estudo tem como unidade de análise as organizações, que foram analisadas a partir do seu perfil, diretrizes de GRH, práticas de GT e definição de talento. A população deste estudo é composta por empresas atuantes no Brasil que buscam reconhecimento por sua avançada gestão de RH e qualidade do ambiente de trabalho. As empresas se inscrevem voluntariamente para participar da survey e têm que atender a dois critérios: contar com, no mínimo, 100 empregados na ocasião da pesquisa e estar operando no mercado nacional há mais de cinco anos. A amostra é do tipo não-probabilística e por conveniência, pois é composta pelas organizações que se inscreveram voluntariamente na pesquisa que disponibilizou os dados para este estudo. Segundo Sampieri et al. (2006), este é um tipo de amostra aleatória em que o pesquisador formula conclusões sobre espécimes que chegam casualmente às suas mãos. Considerando a edição de 2010 da pesquisa adotada contou-se com 541 empresas participantes, sendo que 471 apresentaram os questionários completamente respondidos. Por isso, a amostra deste estudo foi de 471 empresas.

Os dados empíricos coletados foram gerados por questões do tipo fechada ou aberta. Portanto, a forma de análise foi distinta, sendo analisados por meio de estatística descritiva os resultados das questões fechadas e, por análise de conteúdo, as questões abertas. 
Para as questões fechadas realizou-se uma análise quantitativa dos dados usando a estatística descritiva com contagem de frequência simples e relativa (SAMPIERI et al., 2006). Para isso, estratificou-se as respostas, com o auxílio do software Excel, analisando descritivamente as categorias de empresas quanto à existência (ou ausência) de um programa formal de GT e às abordagens adotadas, inclusiva (todos são Talento) ou exclusiva (nem todos são Talento) (ILES et al., 2010).

Os dados empíricos gerados por questões abertas e os teóricos, recolhidos da literatura, foram e analisados por meio de análise de conteúdo. Como opção metodológica, este método foi prioritariamente desenvolvido tendo como referência a Bardin (1977, p. 44) que o define da seguinte maneira: "um conjunto de técnicas de análise das comunicações visando obter por procedimentos sistemáticos e objetivos de descrição do conteúdo das mensagens indicadores (quantitativos ou não) que permitam a inferência de conhecimentos relativos às condições de produção/recepção (variáveis inferidas) destas mensagens".

O método da análise de conteúdo aplicado neste estudo ocorreu por meio das etapas de organização, descrição, inferência e interpretação (BARDIN, 1977). O primeiro processo consiste na organização da análise, no qual as respostas foram inseridas em uma planilha Excel, excluindo-se os nomes das empresas para garantir o anonimato delas. Esta planilha foi inserida no software de análise qualitativa, NVivo versão 10, a fim de que se pudesse analisar estes dados com auxílio de um meio eletrônico, assegurando objetividade e confiabilidade.

Para a descrição dos resultados foram desenvolvidas as etapas de codificação e categorização. A "palavra" foi selecionada como a unidade de registro (o que se conta) e correspondeu ao segmento de conteúdo considerado como unidade de base para a categorização e contagem frequencial. As frases das respostas selecionadas foram tomadas como contexto para a compreensão e codificação da unidade de registro. A regra de enumeração, ou seja, como ocorreu a contagem da unidade de registro, foi adotada de maneira a verificar a frequência da palavra selecionada. Bardin (1977) denomina esta forma de enumeração como abordagem quantitativa.

$\mathrm{Na}$ abordagem quantitativa da análise de conteúdo contou-se com o suporte do software NVivo 10, empregando-se a ferramenta de Word Frequency, que faz a leitura de todas as respostas da questão específica que foi selecionada, apresentando a frequência de palavras que lá constam em uma planilha Excel. Nesta fase, a questão selecionada foi do tipo aberta, na qual as empresas respondentes puderam declarar o que é Talento para elas.

REAd | Porto Alegre - Vol. 23 - No Especial - Dezembro 2017 - p. 158-187 
Encerrado o processo de descrição, iniciou-se o de inferência. A variável de inferência esperada com esta análise é a caracterização dos hábitos linguísticos do emissor, que pode ser expresso a partir de indicadores léxicos que demonstram o estilo do texto, as palavras mais utilizadas e a variedade do vocabulário (BARDIN, 1977). Portanto, foram analisadas as palavras mais frequentes nas definições de Talento declaradas pelas empresas respondentes. Para tanto, após a contagem das palavras das respostas empíricas, selecionou-se uma amostra com os termos que apresentaram frequência relativa igual ou maior que 0,10. Com esta amostra partiu-se para a categorização dos termos encontrados de acordo com a frequência e classe gramatical à qual pertenciam segundo o sentido destas unidades com emparelhamento dos sinônimos e sentidos próximos. Isto é, o critério adotado foi o léxico na perspectiva da Bardin (1977). Isto permitiu calcular três indicadores léxicos: (1) Quociente de Gênero Gramatical, que aponta se o conteúdo é de teor descritivo ou dinâmico; (2) TTR, indicador que mede a variedade do vocabulário utilizado; (3) Núcleo Lexical, que mediu as palavras que constaram em todas as categorias analisadas (BARDIN, 1977).

A descrição analítica permitiu a classificação por temas em uma unidade de significação complexa, que emergiu dos textos analisados na fase teórica deste estudo. Os termos mais frequentes na literatura de Talento constam como resultado teórico na Tabela 2. Esta categoria foi utilizada como comparação com os dados empíricos relativos à pergunta selecionada. $A$ priori, considerou-se como categorias de análise do tipo "caixa" as que surgiram do referencial teórico deste estudo tal como: (1) Gestão de Talentos: Com GT Formal; Sem GT Formal, GT Inclusiva, GT Exclusiva; (2) Talento: Termos mais citados na Literatura de Talento(s)/Talent.

Os resultados gerados possibilitaram refletir sobre a forma dos conceitos empíricos apresentados. O método de análise de conteúdo culminou com o processo de interpretação. No qual, segundo Bardin (1977), foram identificadas as características principais do conteúdo, por meio dos efeitos da mensagem analisada, que resultou no índice de núcleo lexical (geral e empírico). A consolidação dos termos considerados como núcleo lexical empírico geral deu origem às categorias de análise do tipo acervo a posteriori. Isto é, fez emergir os atributos de talento propostos como resultado deste estudo, sendo eles: identificadores e qualificadores. Estes resultados estão apresentados na próxima seção em forma de tabelas, quadros e figuras.

\section{APRESENTAÇÃO E ANÁLISE DOS RESULTADOS}

REAd | Porto Alegre - Vol. 23 - No Especial - Dezembro 2017 - p. 158-187 
Os resultados deste estudo estão apresentados e analisados em três subseções: (3.1) Análise da Literatura Acadêmica sobre Talento e GT; (3.2) As Empresas e a Gestão de Talentos e (3.3) O Termo Talento na Literatura e nas Organizações. Sendo que, na parte 3.1 constam somente os resultados obtidos com a pesquisa bibliométrica sobre Talentos e GT, na subseção 3.2 estão apresentados os dados obtidos por meio do levantamento nas organizações e na subseção 3.3 os dados das subseções anteriores (3.1 e 3.2) são examinados conjuntamente com a finalidade de analisar a produção acadêmica nacional e internacional sobre talento e GT, relacionando-a com a sua prática em organizações que atuam no Brasil.

\subsection{ANÁLISE DA LITERATURA ACADÊMICA SOBRE TALENTO E GT}

Nesta subseção consta a análise do material resultante do levantamento da literatura acadêmica sobre Talento no campo da Administração.

As fontes de maior publicação, de acordo com a quantidade de artigos, foram as seguintes: Harvard Business Review (13); Journal of World Business (11); The International Journal of Human Resource Management (7) e EnANPAD (6), conforme consta na Tabela 2. Destes, o primeiro periódico é de abordagem geral no campo da Gestão e, mesmo assim, apresentou a maior quantidade de publicações sobre o tema. No segundo, houve uma edição especial sobre Gestão Global de Talentos em 2010. No Brasil, a publicação está, predominantemente, concentrada em anais do Encontro Nacional da ANPAD (EnANPAD), tendo sido encontrada somente uma publicação dentre os periódicos nacionais selecionados para esse estudo, a Revista Eletrônica de Administração (REAd).

Tabela 2 - Artigos sobre Talentos em Gestão e GT por Ano e Fonte

\begin{tabular}{|c|c|c|}
\hline Artigos por Ano e Fonte & Talento & $\mathbf{G T} * * *$ \\
\hline 1968 & 1 & \\
\hline Research Management* & 1 & \\
\hline 1990 & 1 & \\
\hline The Journal of Applied Psychology & 1 & \\
\hline 1994 & 1 & \\
\hline Management Science & 1 & \\
\hline 2000 & 2 & \\
\hline Harvard Business Review** & 2 & \\
\hline 2001 & 1 & \\
\hline Harvard Business Review & 1 & 1 \\
\hline
\end{tabular}

REAd | Porto Alegre - Vol. 23 - No Especial - Dezembro 2017 - p. 158-187 
Tabela 2 - Artigos sobre Talentos em Gestão e GT por Ano e Fonte

\begin{tabular}{|c|c|c|}
\hline Artigos por Ano e Fonte & Talento & GT*** \\
\hline 2002 & 3 & \\
\hline Academy of Management Journal** & 1 & \\
\hline Human Resource Management & 1 & \\
\hline Journal of Business and Psychology & 1 & \\
\hline 2003 & 4 & \\
\hline Encontro Nacional da ANPAD - EnANPAD & 2 & \\
\hline Harvard Business Review & 1 & \\
\hline Industrial and Corporate Change & 1 & \\
\hline 2004 & 1 & \\
\hline Human Resource Management Review & 1 & \\
\hline 2005 & 5 & \\
\hline Encontro Nacional da ANPAD - EnANPAD & 1 & \\
\hline Harvard Business Review & 1 & \\
\hline Human Resource Management** & 1 & \\
\hline Journal of World Business** & 1 & \\
\hline The International Journal of Human Resource Management & 1 & \\
\hline 2006 & 2 & \\
\hline Human Resource Management Review & 1 & 1 \\
\hline Revista Eletrônica de Administração - REAd & 1 & \\
\hline 2007 & 1 & \\
\hline Harvard Business Review & 1 & \\
\hline 2008 & 5 & \\
\hline Encontro Nacional da ANPAD - EnANPAD & 2 & \\
\hline Harvard Business Review & 2 & 1 \\
\hline MIT Sloan Management Review & 1 & \\
\hline 2009 & 6 & \\
\hline Harvard Business Review & 1 & \\
\hline Human Resource Management & 1 & \\
\hline Human Resource Management Review & 1 & 1 \\
\hline Journal of International Business Studies & 1 & \\
\hline The International Journal of Human Resource Management & 2 & \\
\hline 2010 & 15 & \\
\hline Academy of Management Annual Meeting Proceedings & 1 & \\
\hline Encontro Nacional da ANPAD - EnANPAD & 1 & \\
\hline Harvard Business Review & 3 & \\
\hline Journal of World Business & 10 & 9 \\
\hline 2011 & 5 & \\
\hline Harvard Business Review & 1 & \\
\hline The International Journal of Human Resource Management & 4 & 2 \\
\hline Total geral & 53 & 15 \\
\hline
\end{tabular}

*O arquivo referente a este artigo não está disponível para download nas fontes pesquisadas.

** Os itens com essa marcação constam, simultaneamente, entre os mais citados e, na busca manual, nos periódicos.

***Os 15 textos de GT estão incluídos nos 52 artigos de Talento.

Fonte: Web of Science (2012).

REAd | Porto Alegre - Vol. 23 - No Especial - Dezembro 2017 - p. 158-187 
Na Tabela 2 pode-se observar, de modo geral, que os textos sobre GT se apresentam com maior frequência a partir de meados dos anos 2000. No campo da gestão a produção sobre Talentos se mostra constante, mas pequena ao longo do período analisado, tendo picos de crescimento a partir de 2009. Isto evidencia a contemporaneidade e o potencial de crescimento desses temas.

Considerando o objetivo específico deste estudo, em que se busca identificar conceitos de talento e de GT no campo da gestão, optou-se por verificar o uso destes termos nos textos selecionados. Os capítulos foram identificados por meio de leitura flutuante, verificando a estrutura de tópicos de cada texto. Os termos foram analisados por meio do recurso de busca de palavras do NVivo 10, que apresentou as ocorrências dos termos de busca no texto e o contexto em que estavam inseridos. Foi verificado, então, manualmente, se estes termos estavam acompanhados de um conceito, ou sendo somente mencionados. A distribuição dos artigos nestas categorias é apresentada na Tabela 3.

Tabela 3 - Artigos de Talento em Gestão e GT, de acordo com o uso do termo de busca

\begin{tabular}{lcc}
\hline \multicolumn{1}{c}{ Classificação } & Talento $(\mathbf{T})$ & Gestão de Talentos (GT)* \\
\hline Menção a T/GT com adjetivos & 41 & 1 \\
Definição sobre T/GT & 10 & 9 \\
Uso de T/GT somente no título & 1 & 5 \\
\hline Total & $\mathbf{5 2}$ & $\mathbf{1 5}$ \\
\hline \multicolumn{4}{c}{ *Os 15 textos de GT estão incluídos nos 52 artigos de Talento. } \\
Fonte: análise da produção acadêmica realizada pelos autores.
\end{tabular}

A partir dos 52 textos selecionados, pôde-se verificar que 30 (58\%) destes continham um capítulo teórico sobre Talento ou GT. Os demais trataram o assunto inserido no capítulo de gestão de pessoas ou somente utilizaram este termo para identificar o seu público de pesquisa. Na análise com o NVivo 10 foi possível verificar a incidência dos termos "Talent" e “Talento(s)", respectivamente, 3015 e 525 vezes no total de artigos analisados. Não foi possível identificar as expressões "GT" e "Talent Management" enquanto locuções, mas os termos "Management" e "Gestão" apareceram 3821 e 163 vezes nos textos, nesta ordem. As palavras "Talent" e "Management" são as mais frequentes no total de textos analisados, conforme recursos analíticos do software utilizado.

Embora, em 58\% dos textos houvesse um capítulo teórico sobre estes temas, pôde-se identificar, na Tabela 3, que prevaleceram as menções a adjetivos ou termos cognatos que caracterizariam os talentos, sem, no entanto, defini-los conceitualmente. Somente em 19\% do total analisado é que se encontrou algum conceito de Talento ou de Gestão de Talentos. Nesta

REAd | Porto Alegre - Vol. 23 - No Especial - Dezembro 2017 - p. 158-187 
contagem não foi considerado se eles eram distintos ou repetições. A referência mais citada para caracterizar a GT é relativa à revisão realizada por Lewis e Heckman (2006). Quanto ao termo Talento não houve um autor que se destacasse quantitativamente.

Além dos artigos nacionais e internacionais analisados, foram selecionados 12 trabalhos de pós-graduação em bancos de teses e dissertações nacionais por mencionarem em seu título o termo Talento e ou GT. Nesta seleção, não foi possível fazer o download de dois arquivos, portanto, foram analisadas somente 10 destas pesquisas. Todas elas eram Dissertações de Mestrado, sendo sete da modalidade Acadêmica e três, da Profissional. Analisando-as pôde-se constatar que a maioria delas (70\%) é de pesquisas qualitativas, classificadas como estudo de caso e relacionadas à Retenção de Talentos. A totalidade delas apresentou um capítulo sobre Talentos ou GT, bem como citou uma definição conceitual para tal. As referências de Talento mais frequentes foram, respectivamente, a de Michaels et al. (2002) e a de Sarsur et al. (2003).

$\mathrm{Na}$ análise deste material, foi possível observar que a maioria dos textos faz somente menções ao termo Talento ou Talent, sem, no entanto, defini-los conceitualmente. Estes dados auxiliam na compreensão da citação de Lewis e Heckman (2006), que foi utilizada como uma das justificativas para este estudo, na qual eles constatam que os termos Talento e GT são polêmicos e pouco definidos na academia.

Entretanto, observou-se que, nos textos analisados, constam adjetivos ou termos cognatos para caracterizar os talentos, mesmo que não estejam em uma definição formal. Para tentar contribuir com o desenvolvimento teórico deste tema, optou-se por investigar o conteúdo deste material. Para isso, com o auxílio do recurso de contagem de palavras do software NVivo, optou-se por listar as palavras existentes nos textos analisados em busca de algum padrão. Isto resultou num total de 17.593 palavras (sem repetição) e 305.855 termos utilizados no geral.

A partir desta lista, foi calculada a frequência ponderada de cada palavra e, devido à quantidade de vocábulos, optou-se por apresentar, neste estudo, os que apresentavam a frequência ponderada acima de 0,10, resultando na seleção de 189 palavras. Além disso, foram considerados para análise os vocábulos classificados gramaticalmente como adjetivo, advérbio, substantivo e verbo, resultando em uma lista com 126 palavras. Estes principais termos e expressões que foram empregados nos textos analisados constam na Tabela 4.

REAd | Porto Alegre - Vol. 23 - No Especial - Dezembro 2017 - p. 158-187 
Tabela 4 - Termos mais frequentes nos textos sobre Talentos no campo da gestão

\begin{tabular}{|c|c|c|c|c|c|c|c|}
\hline Palavra & $\%$ & Palavra & $\%$ & Palavra & $\%$ & Palavra & $\%$ \\
\hline managing & 1,26 & individuals & 0,19 & cultural & 0,13 & terms & 0,11 \\
\hline talent & 0,99 & reviews & 0,19 & focus & 0,13 & tm (talent management) & 0,11 \\
\hline company & 0,47 & empresas & 0,18 & models & 0,13 & world & 0,11 \\
\hline employees & 0,46 & $h r$ & 0,18 & strategy & 0,13 & years & 0,11 \\
\hline organization & 0,41 & important & 0,18 & persons & 0,12 & products & 0,10 \\
\hline develops & 0,41 & needs & 0,18 & attract & 0,12 & ability & 0,10 \\
\hline international & 0,41 & strategic & 0,18 & corporations & 0,12 & adjustments & 0,10 \\
\hline having & 0,39 & differs & 0,17 & experiment & 0,12 & capital & 0,10 \\
\hline business & 0,38 & level & 0,17 & factors & 0,12 & costs & 0,10 \\
\hline firms & 0,36 & relatively & 0,17 & industry & 0,12 & diversity & 0,10 \\
\hline globally & 0,35 & talentos & 0,17 & likely & 0,12 & executives & 0,10 \\
\hline resourcing & 0,35 & positions & 0,16 & making & 0,12 & functions & 0,10 \\
\hline humanities & 0,34 & recruitment & 0,16 & offshoring & 0,12 & innovative & 0,10 \\
\hline more & 0,33 & socially & 0,16 & providing & 0,12 & mais & 0,10 \\
\hline doing & 0,32 & succession & 0,16 & results & 0,12 & many & 0,10 \\
\hline journals & 0,32 & were & 0,16 & some & 0,12 & não & 0,10 \\
\hline performing & 0,32 & all & 0,15 & support & 0,12 & opportunity & 0,10 \\
\hline researchers & 0,29 & between & 0,15 & them & 0,12 & pool & 0,10 \\
\hline we've & 0,28 & decisions & 0,15 & those & 0,12 & professional & 0,10 \\
\hline career & 0,27 & expatriate & 0,15 & timing & 0,12 & services & 0,10 \\
\hline newness & 0,27 & people & 0,15 & value & 0,12 & through & 0,10 \\
\hline high & 0,26 & skills & 0,15 & when & 0,12 & university & 0,10 \\
\hline works & 0,25 & assignments & 0,14 & activity & 0,11 & é & 0,10 \\
\hline can & 0,24 & challenging & 0,14 & changing & 0,11 & & \\
\hline may & 0,24 & how & 0,14 & competence & 0,11 & & \\
\hline using & 0,24 & increase & 0,14 & including & 0,11 & & \\
\hline employs & 0,23 & ours & 0,14 & key & 0,11 & & \\
\hline practicing & 0,23 & processing & 0,14 & knowledge & 0,11 & & \\
\hline studying & 0,23 & role & 0,14 & large & 0,11 & & \\
\hline jobs & 0,22 & who & 0,14 & measuring & 0,11 & & \\
\hline organizational & 0,21 & bases & 0,13 & plans & 0,11 & & \\
\hline also & 0,20 & china & 0,13 & potential & 0,11 & & \\
\hline markets & 0,19 & competitiveness & 0,13 & suggests & 0,11 & & \\
\hline effects & 0,19 & country & 0,13 & systems & 0,11 & & \\
\hline
\end{tabular}

Observando os termos de maior ocorrência nos textos sobre Talentos no campo da gestão, pode-se verificar que são mais frequentes os relacionados ao aspecto global e internacional do talento, seguidos por "resource", que aparece em grande proporção nestes textos, e pelas palavras relacionadas a aspectos de diferenciação. Os adjetivos relacionados a fatores intrínsecos ou de igualdade apresentaram as menores frequências ponderadas nos artigos, abaixo de 0,10 e, portanto, não constaram na Tabela 4.

O termo talento, tal como citado por Lewis e Heckman (2006) é impreciso e há poucas 
definições. Isto pôde ser constatado também por meio da revisão da literatura realizada nesta pesquisa. Na qual foram consideradas publicações até dezembro de 2011 e, no entanto, não foi possível encontrar uma definição padrão para este termo ou que fosse adotada fortemente por diversos pesquisadores. Uma síntese dos conceitos e menções a Talento encontradas nos artigos, dissertações e livros consultados estão expostos no Quadro 1.

Quadro 1 - Principais conceitos e menções sobre talento no campo da gestão

\begin{tabular}{|c|c|}
\hline Talento & Fonte \\
\hline $\begin{array}{l}\text { "The term talent, to begin with, is ambiguous. Sometimes it refers to an } \\
\text { aptitude or ability in the person, and sometimes it refers to talented } \\
\text { performance by the person, behavior which goes beyond the ordinary in } \\
\text { meeting some criterion of desirability." }\end{array}$ & McClelland et al $(1958$, p.1) \\
\hline $\begin{array}{l}\text { "People who had greater mental ability, who were psychologically } \\
\text { compatible with the company's need for innovation and change, who } \\
\text { were skilled administrators and effective decision makers, and who were } \\
\text { emotionally stable yet aggressive." }\end{array}$ & $\begin{array}{l}\text { Jackson e Schuler }(1990, \\
\text { p.234) }\end{array}$ \\
\hline $\begin{array}{l}\text { "In the most general sense, Talent is the sum of a person's abilities - his } \\
\text { or her intrinsic gifts, skills, knowledge, experience, intelligence, } \\
\text { judgment, attitude, character and drive. It also includes his or her } \\
\text { ability to learn and grow" }\end{array}$ & $\begin{array}{l}\text { Handfield-Jones e Axelrod } \\
\text { (2001, p.xii) }\end{array}$ \\
\hline $\begin{array}{l}\text { "Os profissionais identifica dos como jovens talentos são percebidos como } \\
\text { in dividuos que se concentram na faixa dos } 25 \text { a } 30 \text { anos." }\end{array}$ & Sarsur et al (2003, p.16) \\
\hline $\begin{array}{l}\text { "Talent is the combination of skill sets, competencies, and experiences } \\
\text { necessary to perform the work." }\end{array}$ & Berger e Berger (2004, p.233) \\
\hline $\begin{array}{l}\text { "[...] jovens talentos (alunos de últimos anos identificados como destaques } \\
\text { pelos professores dos cursos de admnistração de três principais } \\
\text { universidades de Porto Alegre)". }\end{array}$ & Garay $(2006, p .3)$ \\
\hline "Talent equals competence times commitment times contribution" & Ulrich $(2007$, p. 32) \\
\hline
\end{tabular}

Fonte: análise da revisão de literatura realizada pelos autores.

Identificou-se, nos textos analisados, uma definição específica sobre talento para gestão: “O talento gerencial é a combinação de pensamento estratégico, capacidade de liderança, maturidade emocional, habilidade de comunicação, capacidade para atrair e inspirar outros talentos, instinto empreendedor, habilidades funcionais e a capacidade de entregar resultados" (HANDFIELD-JONES; AXELROD, 2001, p.xiii,).

Mucha (2004) e Ingham (2006) afirmam que o Talento vem se tornando umas das forças que impulsionam o sucesso nos negócios, embora sua definição seja fluida, influenciada pela estratégia organizacional e pelas contingências do ambiente em que se encontra. Contudo, a indefinição deste termo não impede que a ele seja atribuída grande REAd | Porto Alegre - Vol. 23 - No Especial - Dezembro 2017 - p. 158-187 
importância, haja vista, que é a partir deste que se pode compor uma linguagem comum à organização, norteando os componentes da Gestão de Talentos (INGHAM, 2006; TANURE et al., 2007; FERREIRA,2008). Na próxima subseção constam os resultados obtidos com o levantamento de dados nas organizações.

\subsection{AS EMPRESAS E A GESTÃO DE TALENTOS}

Nesta seção são apresentadas as empresas participantes da survey adotada neste estudo, discriminadas em categorias, de acordo com a presença ou ausência de um programa formal de GT e das suas abordagens, inclusiva ou exclusiva. As 471 empresas respondentes empregam 1.475.391 pessoas com vínculo formal de trabalho e são, em sua maioria, de médio e grande porte. Quanto à GT, 75\%, isto é, 353 do total de 471 empresas declararam exercê-la por meio de um Programa Formal de Gestão de Talentos.

Estas empresas, que exercem formalmente a GT, são responsáveis pela gestão de uma força de trabalho com 1.178 .944 profissionais. Verifica-se, assim, que quase $80 \%$ do quadro total de empregados das empresas pesquisadas está envolvido em programas formais de GT.

Entre as questões analisadas, uma indagava se os programas formais de GT consideravam que todos os empregados eram talentos. A partir das respostas concedidas e com o apoio da literatura, constatou-se que das 353 empresas que declararam adotar um programa formal de GT, 73,4\% (259) foram classificadas com uma abordagem exclusiva e $26,6 \%$ (94) com a inclusiva.

Nos dados empíricos analisados foram encontradas definições de talento particulares para cada empresa respondente. O montante de definições analisado (Tabela 5) foi composto por 16.872 palavras, das quais 2.126 eram diferentes. Devido ao grande volume de vocábulos foram selecionados os que apresentaram, em cada categoria, a frequência ponderada igual ou superior a 0,10. Na Tabela 5 constam os indicadores de Quociente de Gênero Gramatical e o Indicador Léxico TTR que possibilitam reconhecer por meio da mensagem analisada o hábito linguístico do emissor, neste caso, das empresas respondentes (BARDIN, 1977).

Por meio do quociente de gênero gramatical (Tabela 5), constatou-se que as respostas analisadas são de estilo descritivo, o que era esperado, já que se tratam de definições conceituais. O indicador léxico TTR demonstrou que há pouca variedade de vocabulário, ou seja, de fato, as organizações estão privilegiando alguns termos na composição de suas 
definições de talento. Quanto ao hábito linguístico do emissor, estes resultados evidenciaram um comportamento convergente destas empresas no que se refere aos atributos de um talento, haja vista, que mesmo tendo apresentado combinações diversas na composição das frases, o estilo de texto foi descritivo e o vocabulário pouco variado, indicando a predominância de alguns termos. Resultado semelhante, também, foi observado na pesquisa da empresa Towers Perrin (2004) citada por Iles et al. (2010).

Tabela 5 - Indicadores da Análise de Expressão das Definições de Talento

\begin{tabular}{|c|c|c|c|c|}
\hline \multirow{2}{*}{ Indicadores da Expressão } & \multirow{2}{*}{$\begin{array}{l}\text { Sem } \\
\text { GT } \\
\text { Formal }\end{array}$} & \multirow{2}{*}{$\begin{array}{l}\text { Com } \\
\text { GT } \\
\text { Formal }\end{array}$} & \multicolumn{2}{|c|}{$\begin{array}{l}\text { Com GT Formal } \\
\text { (por Abordagem) }\end{array}$} \\
\hline & & & $\begin{array}{c}\text { GT } \\
\text { Inclusiva }\end{array}$ & $\begin{array}{c}\text { GT } \\
\text { Exclusiva }\end{array}$ \\
\hline $\begin{array}{l}\text { Quociente de gênero gramatical: } \\
\text { ((Verbo+Advérbio)/(Substantivo+Adjetivo)); Resultado: Maior que } \\
1 \text { - discurso no estilo dinâmico; Menor que } 1 \text { - discurso descritivo }\end{array}$ & 0,45 & 0,50 & 0,34 & 0,42 \\
\hline $\begin{array}{l}\text { Indicador Léxico TTR (type token ratio): mede a variedade ou } \\
\text { pobreza do vocabulário (total de palavras diferentes/total de } \\
\text { palavras); Resultado: Quanto maior o resultado, maior a variedade, } \\
\text { diversidade ou riqueza de vocabulário manifesta no discurso. }\end{array}$ & 0,26 & 0,14 & 0,23 & 0,16 \\
\hline
\end{tabular}
Fonte: elaborada pelos autores a partir dos dados empíricos.

Na próxima seção, consta a análise acerca das definições do termo Talento declaradas pelas organizações e encontradas no levantamento bibliométrico da literatura.

\subsection{O TERMO TALENTO NA LITERATURA ACADÊMICA E NAS ORGANIZAÇÕES}

A fim de atender ao objetivo deste estudo fez-se a comparação entre os dados empíricos e os termos mais citados na literatura acadêmica. Esse resultado foi condensado na Tabela 6 onde ficou em evidência o caráter internacional destes termos, pois os mais frequentes são grafados em inglês.

$\mathrm{Na}$ Tabela 6, os termos foram classificados em categorias, independente do idioma quando eram da mesma classe gramatical e tinham o significado. A análise agregada das palavras mais frequentes demonstrou que nas cinco categorias apresentadas há 44 termos distintos. Observou-se que diversos itens ocorreram, simultaneamente, em mais de uma categoria, enquanto, que outros constaram de forma isolada. Entre estes termos, 22 deles, isto é, $50 \%$ do total foram considerados como núcleo lexical, representando as palavras que são comuns a todas as categorias analisadas. Destes, 12 foram classificados como núcleo lexical empírico e 10, como núcleo lexical geral (empírico e literatura). A interpretação dos termos

REAd | Porto Alegre - Vol. 23 - No Especial - Dezembro 2017 - p. 158-187 
classificados como núcleo lexical geral e empírico permitiu consolidá-los como os atributos de talento resultantes deste estudo no Quadro 2.

Tabela 6 - Distribuição das Palavras mais Frequentes sobre Talento na Literatura e nas Organizações

\begin{tabular}{|c|c|c|c|c|c|c|}
\hline \multirow{4}{*}{ Dist. } & \multirow{4}{*}{ Palavra } & \multicolumn{5}{|c|}{ Categorias } \\
\hline & & \multirow[b]{2}{*}{ Literatura } & \multicolumn{4}{|c|}{ Organizações } \\
\hline & & & $\begin{array}{c}\text { Sem GT } \\
\text { Formal }\end{array}$ & $\begin{array}{c}\text { Com GT } \\
\text { Formal }\end{array}$ & $\begin{array}{c}\text { GT } \\
\text { Inclusiva }\end{array}$ & $\begin{array}{c}\text { GT } \\
\text { Exclusiva }\end{array}$ \\
\hline & & Freq. (\%) & $\begin{array}{c}\text { Freq. } \\
(\%)\end{array}$ & $\begin{array}{c}\text { Freq. } \\
(\%)\end{array}$ & $\begin{array}{c}\text { Freq. } \\
(\%)\end{array}$ & Freq. (\%) \\
\hline \multirow[t]{16}{*}{ Isolada } & Atividades & & 0,4 & & & \\
\hline & Busca & & 0,4 & & & \\
\hline & Business & 0,4 & & & & \\
\hline & Career & 0,3 & & & & \\
\hline & Doing & 0,3 & & & & \\
\hline & Forma & & 0,4 & & & \\
\hline & Globally & 0,4 & & & & \\
\hline & Humanities & 0,3 & & & & \\
\hline & International & 0,4 & & & & \\
\hline & Journals & 0,3 & & & & \\
\hline & Liderança & & & & 0,4 & \\
\hline & Managing & 1,3 & & & & \\
\hline & Newness & 0,3 & & & & \\
\hline & Performing & 0,3 & & & & \\
\hline & Research & 0,3 & & & & \\
\hline & Resourcing & 0,4 & & & & \\
\hline \multirow{4}{*}{$\begin{array}{l}\text { Mais de uma } \\
\text { categoria }\end{array}$} & Crescimento & & & 0,4 & 0,3 & 0,4 \\
\hline & Desempenho & & & 0,5 & & 0,6 \\
\hline & Equipe & & 0,4 & & 0,4 & \\
\hline & tem/having/we've & 0,4 & & 0,4 & & 0,5 \\
\hline & capacidade & & 0,5 & 0,4 & 0,4 & 0,5 \\
\hline & competências & & 0,6 & 0,8 & 0,7 & 0,9 \\
\hline & conhecimento & & 0,5 & 0,5 & 0,4 & 0,5 \\
\hline & É & & 2,3 & 1,7 & 1,7 & 1,7 \\
\hline & habilidades & & 0,8 & 0,6 & 0,5 & 0,6 \\
\hline Empírico & Pessoas & & 1,4 & 1,1 & 1 & 1,2 \\
\hline & potencial & & 0,6 & 0,8 & 0,4 & 0,9 \\
\hline $\begin{array}{l}\text { Núcleo } \\
\text { Lexical }\end{array}$ & Profissional/ profissionais & & 1 & 0,9 & 0,9 & 0,9 \\
\hline & Resultados & & 0,9 & 0,8 & 0,6 & 0,9 \\
\hline & São & & 0,9 & 0,9 & 0,9 & 1 \\
\hline & Valores & & 0,6 & 0,7 & 0,7 & 0,7 \\
\hline & colaborador/ employees & 0,5 & 0,8 & 0,6 & 0,6 & 0,6 \\
\hline & desenvolvimento/development & 0,4 & 0,4 & 0,5 & 0,6 & 0,4 \\
\hline Geral & $\begin{array}{l}\text { empresa/ organização/firm/ } \\
\text { company }\end{array}$ & 0,5 & 1,7 & 1,7 & 1,8 & 1,6 \\
\hline & talento/talent & 1 & 1,6 & 1,9 & 2,1 & 1,9 \\
\hline
\end{tabular}

Fonte: elaborada pelos autores a partir dos dados empíricos.

As palavras destacadas no Quadro 2 retratam a ambiguidade e imprecisão teórica e empírica do termo Talento. Condição esta que já era observada por McClelland et al. (1958) e reafirmada, posteriormente, por Lewis e Heckman (2006). Cabe esclarecer que cada palavra 
que consta na Tabela 6 e no Quadro 2 poderia dar início a uma pesquisa específica e contribuir para o desenvolvimento da literatura deste tema. Entende-se que isto extrapolaria o objetivo proposto inicialmente. Portanto, tal abordagem seria indicada para estudos futuros sobre o assunto.

Quadro 2 - Principais atributos teóricos e empíricos de talento em Administração

\begin{tabular}{|c|c|c|}
\hline \multicolumn{2}{|r|}{ Categorias } & Vocábulos \\
\hline \multirow{2}{*}{ Identificadores } & $\begin{array}{l}\text { Menção aos in dividuos nos } \\
\text { programas de GT }\end{array}$ & $\begin{array}{l}\text { Colab orador, pes soas, pro fissionais, } \\
\text { talento; }\end{array}$ \\
\hline & $\begin{array}{l}\text { Menção ao ambiente no qual } \\
\text { estes Talentos atuam }\end{array}$ & Empresa e org anização. \\
\hline Qualificadores & $\begin{array}{l}\text { Atributos de Talento relativos à } \\
\text { abordagem de GT que for } \\
\text { adotad a pela organização }\end{array}$ & $\begin{array}{l}\text { Comp etên cia, capacidade, habilidade, } \\
\text { conhecimento, resultad o, } \\
\text { desenvolvimento, poten cial e valores. }\end{array}$ \\
\hline
\end{tabular}

Fonte: elaborado pelos autores a partir da análise.

A análise do referencial teórico reunido neste estudo, possibilitou uma compreensão acerca da diversidade do termo Talento, da GT e do contexto e dinâmica que relaciona esses temas com a GRH e a GERH. Os dados empíricos possibilitaram identificar a presença de programas formais de GT no país, suas abordagens inclusiva e exclusiva e as palavras mais utilizadas para se referir aos talentos nestas organizações, comparando-as com as adotadas na literatura no campo da Administração. Dessa forma, elaborou-se o esquema apresentado na Figura 1.

Considerando o objetivo deste estudo e a produção acadêmica ao longo dos anos analisados, verificou-se um desenvolvimento de pesquisas e publicações sobre Talentos e GT. Porém, são poucos os textos que se dedicaram a construir ou discutir este assunto enquanto teoria. Não se pode afirmar, somente por meio dos dados analisados neste estudo, se há suficiente ou insuficiente consolidação teórica sobre este tema. Mas, ao constatar a fluidez e imprecisão do conceito de Talento, é possível inferir que não há sentido em buscar uma definição única para o termo na academia. Uma definição de Talento somente tem sentido, dentro de um domínio específico ou no seu contexto de uso, como por exemplo, aquela dada pela particularidade da organização em que será realizada a sua gestão.

A singularidade do conceito de Talento para cada organização e o enfoque das abordagens de Gestão de Talentos configuram a sua relação teórica com a GERH (Figura 1). Isto pode explicar sua variabilidade que é consequência da busca de alinhamento com a REAd | Porto Alegre - Vol. 23 - No Especial - Dezembro 2017 - p. 158-187 
estratégia organizacional, a performance diferenciada e a vantagem competitiva de cada organização.

Figura 1 - Gestão de Talentos e Talentos em Gestão: contexto acadêmico e organizacional

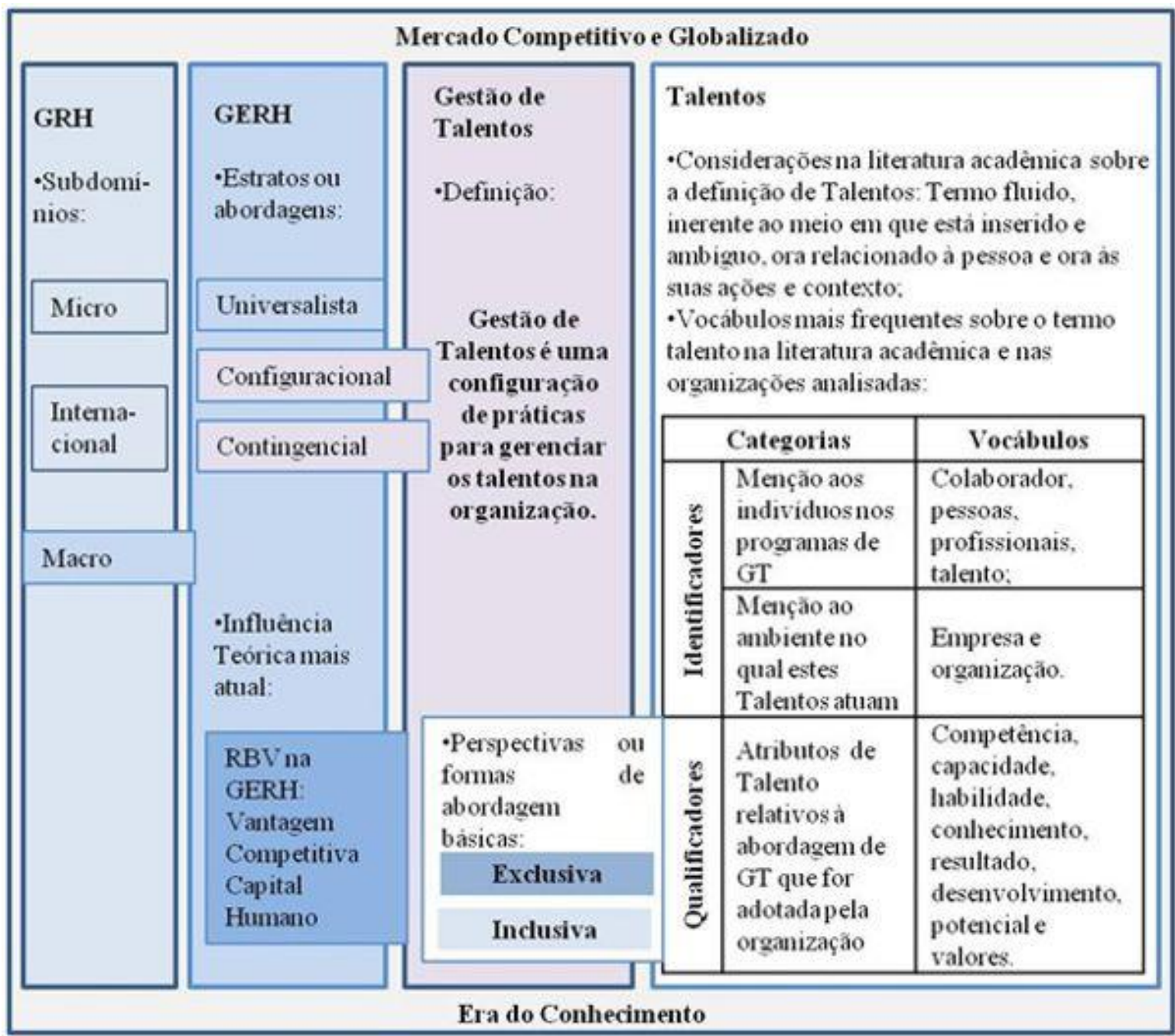

Fonte: elaborada pelos autores a partir dos dados empíricos.

\section{CONSIDERAÇÕES FINAIS}

No objetivo central deste estudo foi proposto analisar a relação entre a produção acadêmica e a utilização no meio corporativo das práticas de GT e definições de Talento em Administração. Embora, não tenha sido encontrado um conceito que se repetisse acentuadamente, constatou-se, por meio da técnica de análise da expressão, que as respostas declaradas pelas empresas eram de estilo descritivo e com um vocabulário pouco diverso. Isto indicou que, mesmo não tendo uma definição comum e usual de talento, houve termos que 
apareceram em mais de uma resposta. Desta forma, fez-se uma contagem de palavras nas respostas, resultando em uma listagem dos termos mais frequentes nas definições empíricas de talento. Por fim, esta relação foi comparada aos termos mais frequentes nos textos da literatura acadêmica sobre Talentos no campo da Administração, que foram coletados na fase de revisão de literatura desta pesquisa, resultando nos atributos identificadores e qualificadores de talentos propostos como resultado deste estudo.

Durante o estudo procurou-se relacionar os resultados empíricos à literatura analisada. Assim, verificou-se que a literatura de GT é convergente em alguns aspectos com a de Gestão Estratégica de RH. Isto gerou o esquema apresentado na Figura 1 referente ao contexto acadêmico e organizacional da Gestão de Talentos e dos Talentos em Gestão. No que se refere às perspectivas e práticas emergentes da área, tais como: o alinhamento com a estratégia organizacional, a busca pela vantagem competitiva e o caráter contingente e configuracional desta gestão. Acredita-se que isto se deve à particularidade e fluidez do termo Talento e à abordagem que propõe a diferenciação destes na população organizacional.

Constatou-se que as organizações apresentam intenção em praticar a Gestão de Talentos, sendo o seu desenvolvimento prático e teórico um desafio para o meio corporativo e para a academia. Todavia, não está claro o impacto e consequências que essa gestão pode ter na estratégia e nos resultados organizacionais, nem suas implicações no clima organizacional. Verificou-se o crescimento das publicações relacionadas a este assunto no campo da Administração e a sua prática emergente e formal (inclusiva ou exclusiva) em organizações atuantes no país.

Este estudo se limitou ao estilo descritivo de análise. Não foi possível, assim, aprofundar a pesquisa de maneira a fornecer maiores explicações para os resultados. Metodologicamente, se restringiu à utilização de dados secundários, o que não permitiu o acesso e a observação direta do ambiente das organizações analisadas. Sugerem-se, para estudos futuros, técnicas de estudo de caso longitudinais, que possam acompanhar em profundidade os resultados dessa prática nas organizações. Indicam-se, também, estudos que busquem apontar como as empresas podem implementar a GT de modo estratégico e a possibilidade de identificar precocemente os talentos em gestão. 


\section{REFERÊNCIAS}

ALVARENGA, L. Bibliometria e arqueologia do saber de Michel Foucault: traços de identidade teórico-metodológica. Revista Ciência da Informação [online], v.27, n. 3, 1998. Disponível em: http://revista.ibict.br/ciinf/article/view/778/807. Acesso em: 18 mar. 2016. AXELROD, E. L., HANDFIELD-JONES, H.; WELSH, T. A. War for talent: part two. McKinsey Quarterly, spring, n. 2, p. 9-12, 2001.

BARDIN, L. Análise de Conteúdo. Lisboa: Edições 70, 1977.

BARNEY, J. B. Firm resources and sustained competitive advantage. Journal of Management, 17, p. 99-120, 1991.

BARNEY, J. B. Firm resources and sustained competitive advantage. Journal of Management, v. 17, n. 1, p. 99-120, 1991.

BERGER, L. A.; BERGER, D. R. The talent management handbook: creating organizational excellence by identifying, cdeveloping, and promoting your best people. New York: McGraw-Hill, 2004.

BOXALL, P.; PURCELL, J. Strategy and Human Resources Management. New York: Palgrave Macmillan, 2008.

BOXALL, P.; PURCELL, J.; WRIGHT, P. Human Resource Management: Scope, Analysis, and Significance. BOXALL, P.; PURCELL, J.; WRIGHT, P. (Orgs). The Oxford Handbook of Human Resource Management. Oxford University Press, 2008. p. 1-16.

CROSSAN, M. M.; APAYDIN, M. A multi-dimensional framework of organizational innovation: a systematic review of the literature. Journal of Management Studies, v. 47, n. 6, p. 1154-1191, 2010.

EASTERBY-SMITH, M.; THORPE, R.; LOWE, A. Pesquisa gerencial em administração: um guia para monografias, dissertações, pesquisas internas e trabalhos em consultoria. São Paulo: Pioneira, 1999.

FARNDALE, E. SCULLION, H.; SPARROW, P. The role of the corporate HR function in global talent management. Journal of World Business, v. 45, n. 2, p. 161-168, 2010. FERREIRA, A. M. Políticas e práticas de gestão de pessoas como fatores de retenção de jovens talentos: um estudo com trainees de empresa brasileira do setor siderúrgico. $220 \mathrm{f}$. Dissertação (Mestrado) - Curso de Administração, Pontifícia Universidade Católica de Minas Gerais, Belo Horizonte, 2008. Disponível em:

REAd | Porto Alegre - Vol. 23 - No Especial - Dezembro 2017 - p. 158-187 
http://www.biblioteca.pucminas.br/teses/Administracao_FerreiraAM_1.pdf. Acesso em: 20 ago. 2012.

FERRIS, G. R.; HOCHWARTER, W. A.; BUCKLEY, M. R.; HARRELL-COOK, G.; FRINK, D. D. Human Resources management: some new directions. Journal of Management, v. 25, n. 3, p. 385-415, 1999.

FISCHER, A. L.; ALBUQUERQUE, L. G. (Coord.). Relatório Delphi-RH 2010: tendências em gestão de pessoas nas empresas brasileiras. São Paulo: PROGEP-FIA, 2010.

FREITAG; B. B.; FISCHER, A. F. Programas Formais de gestão de talentos no brasil: uma realidade? In: Encontro Nacional da ANPAD - EnANPAD, 2013, Rio de Janeiro. Anais... XXXVII EnANPAD. Rio de Janeiro: ANPAD, 2013.

FREITAG, B. B.; OHTSUKI, C. H.; FERREIRA, M. A. A. A gestão de talentos no campo da Gestão de Pessoas: tema emergente? In: Encontro Nacional da ANPAD - EnANPAD, 2012, Rio de Janeiro. Anais... XXXVI EnANPAD. Rio de Janeiro: ANPAD, 2012.

GARAY, A. B. S. A Responsabilidade Social Corporativa (RSC) como elemento de atração de talentos: percepção dos alunos destaques do curso de Administração. Revista Eletrônica de Administração, v. 12, n. 3, mais-jun 2006.

HANDFIELD-JONES, H.; AXELROD, B. The war for talent. Harvard: Harvard Business School Press, 2001.

ILES, P. CHUAI, X.; PREECE, D. Talent management and HRM in multinational companies in Beijing: definitions, differences and diversity. Journal of World Business, v. 45, n. 2, p.179-189, 2010.

INGHAM, J. Closing the talent management gap. Strategic Human Resources Review, v.5, n. 3, p. 20-23, 2006.

JACKSON, S. E.; SCHULER, R. S. Human Resource planning challenges for industrial / organizational psychologists. American Psychologist, v. 45, n. 2, p. 223-239, 1990.

JCR. Journal Citation Reports. Disponível em:

http://thomsonreuters.com/products_services/science/science_products/a-

z/journal_citation_reports/. Acesso em: 20 ago. 2011.

KAUFMAN, B. E. The development of HRM in historical and international perspective.

BOXALL, P.; PURCELL, J.; WRIGHT, P. (Orgs). The Oxford Handbook of Human

Resource Management. Oxford University Press, 2008. p. 20-47.

LEGGE, K. Human Resource Management: rethorics and realities. New York: Palgrave

REAd | Porto Alegre - Vol. 23 - No Especial - Dezembro 2017 - p. 158-187 
Macmillan, 2005.

LENGNICK-HALL, M. L.; LENGNICK-HALL, C. A.; ANDRADE, L. S.; DRAKE, B. Strategic human resource management: the evolution of the field. Human Resource Management Review, v. 19, n. 2, p. 64-85, 2009.

LEWIS, R. E.; HECKMAN, R. J. Talent management: A critical review. Human Resource Management Review, v. 16, p. 139 - 154, 2006.

MACIAS-CHAPULA, C. A. O papel da informetria e da cienciometria e sua perspectiva nacional e internacional. Revista Ciência da Informação. $C i$. Inf. [online], v. 27, n. 2, p. 134-140, 1998. Disponível em: http://dx.doi.org/10.1590/S0100-19651998000200005.

Acesso em: 20 ago.2012.

MARTIN-ALCAZAR, F.; ROMERO-FERNANDEZ, P.; SANCHEZ-GARDEY, G. et al. Strategic human resource management: integrating the universalistic, contingent, configurational and contextual perspectives. The International Journal of Human Resource Management, v. 16, n. 5, p. 633-659, 2005.

McCLELLAND, D. C.; et al. Talent and society: new perspectives in the identification of talent. New Jersey: Princeton, 1958.

MICHAELS, E.; HANDFIELD-JONES, H.; AXELROD, B. A Guerra do Talento. Rio de Janeiro: Campus, 2002.

MILES, R. E.; SNOW, C. C. Designing Strategic Human Resources Systems. Organizational Dynamics, v. 13, n. 1, p. 36-52, 1984.

MUCHA, R. T. The Art and Science of Talent Management. Organizational Development Journal, v. 22, n. 4, p. 96-100, 2004.

SAMPIERI, R. H.; COLLADO, C. F.; LUCIO, P. B. Metodologia de pesquisa. $3^{\text {a }}$ Ed. São Paulo: McGrall Hill, 2006,

SARSUR, A. M.; PEDROSA, R. R.; SANT’ANNA, A. DE S. Onde estão os talentos? Onde está a Gestão de Recursos Humanos? In: Encontro Nacional da ANPAD - EnANPAD.

Anais... p.1-17, 2003.

SELLTIZ, C.; WRIGHTSMAN, L. S.; COOK, S. W. Métodos de pesquisa nas relações sociais. São Paulo: EPU, 1987.

SHRM. Workplace forecast: The Top Workplace Trends According to HR Professionals. Society for Human Resource Management, 64p., fev. 2011. Disponível em: https://www.shrm.org/hr-today/news/hr-magazine/documents/11-0014wpf_posting_6.pdf.

REAd | Porto Alegre - Vol. 23 - No Especial - Dezembro 2017 - p. 158-187 
Acesso em: 20 ago. 2012.

TANURE, B.; EVANS, P.; PUCIK, V. A gestão de pessoas no Brasil: virtudes e pecados capitais. Rio de Janeiro: Elsevier, 2007.

TOWERS PERRIN. Look closer: managing today's talent to create tomorrow's leaders.

2004. Disponível em:

<http://www.towersperrin.com/tp/getwebcachedoc?webc=HRS/GBR/2004/200406/talent_Ex ec_Summary.pdf>. Acesso em: 20 Ago. 2012.

TRANFIELD, D., DENYER, D.; SMART, P. Towards a methodology for developing evidence-informed management knowledge by means of systematic review. British Journal of Management, v. 14, n. 3, p. 207-222, 2003.

ULRICH, D. The Talent Trifecta. Workforce Management, v. 86, n. 15, p. 32-33, 2007.

Web of Science. Base de dados da ISI Web of Knowledge. Disponível em:

http://images.webofknowledge.com/WOK40/help/WOK/h_database.html\#ccr. Acesso em: 17 nov. 2012.

WebQualis. Plataforma do Índice Qualis da CAPES. Disponível em:

http://qualis.capes.gov.br/webqualis/. Acesso em: 20 ago. 2011.

WRIGHT, P. M.; DUNFORD, B. B.; SNELL, S. A. Human resources and the resource based view of the firm. Journal of Management, v. 27, n. 6, p. 701-721, 2001.

WRIGHT, P. M.; MCMAHAN, G. C. Theoretical perspectives for strategic human resource management. Journal of Management, v. 18, n. 2, p. 295-320, 1992.

REAd | Porto Alegre - Vol. 23 - No Especial - Dezembro 2017 - p. 158-187 